\title{
RELACIONES ANTIGUAS ENTRE ESPAÑA Y LOS PAÍSES BAJOS Y PROBLEMAS DE LOS PRÉSTAMOS HOLANDESES (FLAMENCOS) EN CASTELLANO
}

Las relaciones entre España y los Países Bajos se inician a partir del siglo xII en que marinos y comerciantes flamencos, holandeses y frisones zarpan de los puertos del Mar del Norte con sus buques cargados de mercancías, en especial de tejidos, con destino a la Península Ibérica, y asimismo como consecuencia de las Cruzadas y de las peregrinaciones a Santiago de Compostela. Sabemos que los tejidos fabricados en Flandes y enviados a España desde el centro comercial de Brujas no llegaron a ella antes de la segunda mitad del siglo xirr. Las mercancias procedentes de Europa Occidental y principalmente de Flandes tenian como vía de acceso en general, aunque no exclusivamente, los puertos del norte: Santander, Castro Urdiales, Iaredo, San Vicente de la Barquera, y en el siglo xiv existía aún entre estos puertos y Flandes un activo intercambio comercial. En las tarifas aduaneras de estos cuatro puertos, que datan de fines del siglo xrrr, encontramos algunas perifrasis, tales como pannos reforçados d'Ipre, pannos de Ypre planos \& viados, pannos de Gant, ensays de Bruias, estanfortes de Brujas, para indicar tejidos procedentes de las ciudades flamencas de Ypres, Gante y Brujas. Pero, ya antes de finalizar el siglo xirr, los tejidos mencionados llegaron a España por el Sur. En efecto: hallamos ya en I268, en las Cortes de Jerez, expresiones como panno de Ipre, ensay de Ypre, camelin de Gante, panno tinto de Gante, ensay de Brujas ${ }^{1}$. Estas perífrasis han dado origen a los antiguos nombres de tejidos españoles, como ypre, atestiguado en el siglo xIv por Pero López de Ayala, Rimado de Palacio (cfr. aragonés ypre, documentado en I402); gante, documentado ya en el siglo XIV en las Cortes de Valladolid y. brujas, del que existe testimonio del siglo xirr. Tales antiguas denominaciones de te-

1 B. I. VIDos, Prestito, espansione e migrazione dei termini tecnici nelle lingue romanze e non romanze. Problemi, melodo e risultati. Biblioteca dell "Archivum Romanicum», Serie II, Linguistica, vol. 3I. Florencia, I965, pp. 247-250. 
jidos (ypre, brujas) han caldo en desuso y sólo gante «especie de lienzo crudon figura en el Diccionario de la Real Academia Española ${ }^{1 .}$

Resumiendo lo antes expuesto, podemos afirmar que sería un error considerar los vocablos españoles ypre, gante y brujas, que proceden de las ciudades flamencas Ypre, Gante y Brujas, como préstamos flamencos. Ninguna de estas voces fue tomada en préstamo del flamenco por los españoles en el siglo xru. Estos, al importar de dichas ciudades flamencas los mencionados tejidos, que no tenfan todavía denominación, se linitaron a distinguirlos con sendas perífrasis: panno de Ypre, etc., que fueron las que, al simplificarse posteriormente, dieron nombre a los tejidos conocidos como ypre, gante, brujas. No se trata, pues, de préstamos flamencos en castellano, sino de una creación lingǘstica española, consecuencia de un proceso económico flamenco-español ${ }^{2}$.

Después de los primeros intercambios comerciales entre España y los Paises Bajos, que se efectuaron en los siglos XIr-XIV, como queda expuesto, principalmente por vía maritima, las relaciones se intensificaron a fincs del siglo xV y a principios del siglo xvI, cuando Flandes y Holanda entraron a formar parte de la gran monarquía española bajo los reinados de Felipe el Hermoso y de Carlos V ${ }^{3}$. Más adelante, como consecuencia de la guerra de Flandes y especialmente al establecerse allf el ejército y la marina españoles, durante el reinado de Felipe II, las relaciones se hicieron más intensas todavía. En I573 habia en los tercios del duque de Alba que combatian en Flandes 7.900 soldados españoles ${ }^{4} \mathrm{y}$ el primer piloto de la Armada Invencible de Felipe II era holandés ${ }^{5}$. Estas relaciones fueron estrechándose más y más durante el reinado de Felipe IV (I62I-I665), al aumentar las expediciones militares a los Países Bajos. En los 44 años que duró su reinado, tan sólo durante seis los Faíses Bajos no fueron teatro de guerra ${ }^{\circ}$. Es sabido que, durante dichas campañas, muchos holandeses estaban al servicio de los españoles $y$, a su vez, muchos españoles militaban en las filas

1 Vmos, Prestito., pp. I89-195.

2 Prestito., p. 209.

3 Prestilo., p. 254.

- J. HERBIILON, Elements espagnols en wallon et dans le franfais des anciens Pay's-Bas. Mémoires de la commission royal de toponymie et de dialectologie (Section wallonne), Io. Lieja, I96I, p. 25, nota $x$.

- J. BROUTVER, Over Spanjaarden in de Nederlanden in het begin van den tachtigjarigen oorlog, en Handelingen van het vijftiende Nederlandsche philologencongres. Growinga, I934, p. 65.

- HERBIIION, Eléments., p. 25, nota 3. 
holandesas, como, por ejemplo, Alonso de Venegas de Andújar, Manzano, que era de una aldea cercana a Ocaña, Alonso López, etc. ${ }^{1}$.

Es natural que, como consecuencia de las sucesivas campañas militares en Flandes y Holanda, varias palabras holandesas se incorporasen al castellano, principalnucute en el campo náutico, en el cual han sobresalido los holandeses en todo tiempo. En cuantó a las palabras holandesas incorporadas al castellano, el problema principal reside en establecer si las voces holandesas llegaron al castellano directamente o si lo hicieron a través del francés. Se sabe que, durante la ocupación española, además del bilingüismo francés (valón)-holandés (flamenco), que perdura aún hoy en Bélgica, el castellano estaba de moda en los Países Bajos. Sus habitantes, integrados en la gran monarquía española, se dedicaron al estudio del castellano ya durante el reinado de Carlos $\mathrm{V}$ (quien por su crianza en Flandes, todavía en I5I8, a los dos años de subir al trono, se mostraba incapaz de sostener un diálogo con sus súbditos españoles). Gramáticas y diccionarios para el estudio del español, destinados a los flamencos, comenzaron a salir a luz desde 1520 , introduciéndose el castellano, aunque no sin protestas, en la correspondencia administrativa y política ${ }^{2}$. Los jesuitas llegados de España renovaron la enseñanza, y la Universidad de Lovaina acogió a profesores españoles, entre ellos al filósofo Juan Luis Vives ${ }^{3}$, amigo de Erasmo. I a influencia española fue la más importante y duradera en la población flamenca de los Países Bajos y, de modo especial, en Amberes las costumbres españolas dejaron profunda huella en los ambientes ricos y en la burguesía. En Flandes, durante el siglo xvir, el dominio cultural del francés encontró en el castellano una viva competencia, llegando a ser éste, junto al francés, la segunda lengua de la aristocracia flamenca 4 .

Dado que en los Países Bajos,en los siglos XVI y XVII, bajo la soberanía española, el castellano era de uso corriente junto al francés (valón) $\zeta$ al holandés (flamenco), lenguas oficiales aún hoy, las palabras holandesas (flamencas) presentes asimismo en el francés, pudieron llegar al español procedentes de éste y no directamente del holandés. Por lo tanto, el que una palabra española conste en un documento de la época de las guerras de Flandes o en una crónica de las mismas, no es sufi-

1 Brouwer, Over Spanjaarden in de Nederlanden, pp. 65-66.

2 VIDOS, Prestito, pp. 254-255.

s Sobre las ideas lingüisticas de Vives véase el importante articulo, recientemente publicado, de E. Coseriv, Zur Sprachtheorie von Juan Vives, en Festschrift zum 65 Geburtstag Walter Mönch. Heidelberg, I971, pp. 234-255.

- Hremilion, Eléments, p. 21, nota I, 22, 24. Véase taunbién A. FARINELLI, Divagaciones hispánicas. Discursos y estudios criticos. Barcelona, 1936, t. II, p. 47. 
ciente para afirmar que haya pasado al español directamente del holandés, por existir dicha palabra de antiguo, o al mismo tiempo también en el francés. Corominas ${ }^{1}$ sostiene, por ejemplo, que la palabra española dique 'muro o reparo artificial hecho para contener las aguas', atestiguada en I625 en la Historia de la guerra de Flandes de Carlos Coloma, procede, por eso, directamente del holandés dijk y mo a través del francés, en donde el préstamo holandés digue es una voz viva a partir del siglo xiv. La pronunciación de la palabra holandesa dijk, con el diptongo èy no ofrece dificultad alguna, porque se pronunció coun una $i$ larga hasta fines de la Edad Media en holandés y tal se pronuncia aún hoy en los dialectos de la Holanda oriental. La palabra española dique, pues, puede haber venido, bien directamente del holandés ${ }^{2}$, bien a través del francés. Como vamos a ver a continuación, el hecho de que una voz española de origen holandés aparezca por vez primera en el ambiente francés-flamenco-español durante las guerras de Flandes, puede ser indicio de que la voz holandesa no habla penetrado en español directamente, sino a través del francés, tanto si la palabra francesa se registra desde antiguo como si aparece por primera vez en dicho ambiente francés-flamenco-español.

Tenemos, pues, la seguridad de que una palabra española es préstamo directo de una holandesa (flamenca), únicamente cuando dicha voz holandesa no existe en francés o si la forma francesa de una palabra derivada del holandés difiere completamente de la de la voz española. Es el caso, por ejemplo, del castellano escaparate 'especie de alacena o armario, con puertas de vidrios o cristales en la parte exterior', documentada ya en I6II del holandés (flamenco) schaprade ${ }^{3}$, que no existe en francés o en el caso de la palabra española boya 'cuerpo flotante. sujeto al fondo del mar', atestiguada en el siglo xIv, que procede directamente del medio neerlandés bo(e)ye y no a través del francés bouée, que difiere completamente de la forma española, a pesar de tener ambas palabras el mismo origen holandés 4 .

1 J. Coroninas, Diccionario critico etimológico de la lengua castellana, Berца, I955, II, p. I76.

2 M.-F. VAIKHOFF, Préstamos de lenguas modernas, en Enciclopedia ling̨ǘstica hispdnica. Elementos constitutivos del español, t. II. Madrid, I966, p. 367.

3 M. VALKinOFF, Over de Nederlandse woorden in het Spaans, Portugues en Katalaans, en Handelingen van het XVIII' Vlaanse Filologencongres. Gante, r949, p. I42; M. VALKHOFF, Echanges Nérlando-Romans en France et dans la Pminsule Ibérique, en Revista da Faculdade de Letras de Lisboa, I955, XXI, p. I6; CoROunas, op. cit., II, p. 329; VAInuOFr, Prestamos, p. 367.

- VALKuOFF, Echanges, p. I7; 13. E. Vwoos, Etymologie organique, en Revue de linguistique romane, 1957, XXI, pp. 93-105; Vioos, Prestito, pp. 27:-279. 
Es de suma importancia establecer dónde tuvo lugar el préstamo holandés (flamenco) o francés en castellano. Pongamos, ante todo, un ejemplo para precisar el ambiente y la fecha de un préstamo francés en castellano. Para la palabra española finanzas 'hacienda, negocios, banca, asuntos económicos' ${ }^{2}$, que es evidentemente un galicismo, no hallamos en los diccionarios españoles ninguna documentación, lo que parece indicar sería un préstamo reciente. Según W. von Wartburg ${ }^{2}$ la voz francesa pasó, a excepción del español, al italiano (finanza), al portugués (finanças), al inglés (finances), al holandés (financien) y al alemán (Finanzen). Es seguro, no obstante, que el castellano tomó prestada la voz francesa finances en los Países Bajos meridionales, es decir, en Bélgica, en el ambiente francés-español alli existente ya a principios del siglo xvrr, como prueba el gran diccionario trilingüe españolfrancés-flamenco, publicado en Amberes en I639, en el que se lee: esp. finan ças "finances, deniers, geldt/financie" ${ }^{3}$. También sabemos que en Bruselas la institución nacional Conseil des Finances fue conocida entre los españoles en el siglo Xvir por Conscjo de Finan fas ${ }^{4}$ en lugar de serlo con la denominación española Conscjo de Hazienda ${ }^{5}$. Hay que añadir que Calderón (I600-I68r), quien, al parecer, estuvo en Flandes, quizá prestando servicio en el ejército español ${ }^{6}$, dice, en la primera escena de su drama El sitio de Breda, sitio que tuvo lugar en $x 625$, hablando de las diversas tropas del ejército español, lo siguiente:

1 Diccionario manual e ilustrado de la lengua española. Real Academia Española. Madrid, I927, sul verbo finanzas; Pequeño Larousse ilustrado, adaptación española de M. DE TORO y GISBERT. Paris, I93I, s. v. finanzas; Vox. Diccionario general ilustrado de la lengua española. Segunda edición corregida y notablemente ampliada poṛ S. GIII GAYA. Barcelona, I953, s. v. finanzas. Véase ¿ Finanzas o hacienda?, en A. ROSENBLAT, Buenas y malas palabras en el castellano de Venezuela. Caracas-Madrid, r960, pp. 369-373.

2 Französisches etymologisches Wörterbuch. Ireipzig-Jerlin, I934, III, p. 560, nota 7 .

3 El grande dictionario y thesoro de las tres lenguas, Española, Francesa y Flamenca, con todos los nombres de los Reynos, Ciudades y lugares del Mundo. T'Hantvverpen By Caes Ioachim Trognesius, r639, s. v. finanças.

- J. IrEtivnre, La secrétairerie d'Etat et de Guerre sous le régime espagnol (I594-I7Ir). Bruselas, r934, p. I56 (citado por HerRnION, Elements, p. 43).

5 H. Lonchax, La rivalité de la France et de l'Espagne aux Pays-Bas (1635I700). Etude d'histoire diplomatique et militaire. Bruselas, I896, capitulo II, p. 53 , nota I (citado por HIRBII, EN, Elements, p. 43).

- Ii. Frutos Cortés, Calderón de la Barca. Clásicos Labor, IX. Barcelona, 1949, p. IS. 
'Las del pais que llaman escogidos

Son dos mil, de felizes esperanzas;

$Y$ seis mil y ochocientos prevenidos

De los que llaman gente de finanzas' 1

La gente de finanzas eran tropas pagadas por el Consejo de Financas de los Países Bajos, a diferencia de los Ejércitos del Rey, llamados simplemente Ejército, cuyos regimientos eran pagados con dinero del Tesoro español ${ }^{2}$. Vemos, por tanto, la importancia que tuvo el ambiente francés-flamenco-español del Sur de los Paises Bajos, en donde tuvo lugar el préstamo francés en español ${ }^{3}$. En resumen, la palabra española finanzas no es un simple préstamo francés, sino un préstamo francés que se efectuó en los Países Bajos del Sur (Bélgica), en la época de las guerras de Flandes y de la dominación española.

Veamos, ahora, basándonos en esta consideración metodológica, un ejemplo en el que una voz holandesa (flamenca) pasa al castellano a través del fraucés o directamente del holandés (flamenco) en un ambiente francés-flamenco-español. La palabra francesa caremesse, procedente del medio neerlandés kermesse o carmesse 'misa (feria) de la iglesia', se encuentra por primera vez en 5566 con el significado de 'fête du village' en la correspondencia del cardenal Antonio de Granvelle (I565-I583), el cual vivió de I5I 7 a I586 y fue ministro de Carlos V y de Felipe II, y gobernador adjunto de los Paises Bajos con Margarita de Austria; en definitiva: en un ambiente francés-holandés (flamenco)español. La voz car(e)messe, propia de los dialectos valones y documentada en I745, se vuelve de uso corriente con la forma kermesse, que se refiere, en un principio, a la fiesta del pueblo flamenco y se generaliza luego con el significado de 'gran fiesta pública' 4. Ahora bien, en castellano encontramos aisladamente la palabra caramesia en las crónicas de las guerras de Flandes escritas por el sargento mayor del ejército español Alonso Vázquez, quien participó personalmente en ellas, crónicas que van de 1577 a I590. Alonso Vázquez, de Toledo, valiente capitán a las órdenes de Alejandro Farnese, gran general español y desde I57 $S$ gobernador de los Países Bajos, dedicó sus crónicas al rey Felipe IV en I624. Dichas crónicas, que relatan con admirable exactitud las cam-

1 Biblioleca de Autores Españoles, t. 7. Obras de D. Pedro Calderón de la Barca, I, p. IIo.

2 Lonchax, La rivalite de la France et de l'Espagne, pp. 355-356.

- Para la importancia de los diferentes ambientes en el proceso del préstamo véase VIDOS, Prestito, pp. 247-268.

- W. von Wartburg, FEW, II, r, p. 605; XVI, p. $3 I_{4}$. 
pañas de Flandes, no sólo son un retrato fiel de la España militar de la época, sino una interesantísima descripción de la vida pública y privada de Holanda y Flandes de entonces ${ }^{1}$. La palabra caramesia se lèe en el siguiente pasaje de dichas crónicas (en donde se refiere más bien a fiestas militares): « $\ldots$ y en las procesiones que hacen, a las cuales llaman humegangas, y a las demás fiestas caramesias oferias, lleva siempre el mejor lugar, y como ya he escrito, en tales actos van todos con sus armas y bandera en orden de guerra como si hubieran de pelear, guiados de sus Capitanes" ${ }^{2}$. Carainesia, voz españolizada en este pasaje, que no se encuentra en ningún diccionario, no es más que la transformación o españolización personal que hace Alonso Vázquez de la palabra francesa caremesse, documentada en I566, o del medio neerlandés (flamenco) kermesse, carmesse.

Observemos, ahora, cóno suenan las palabras holandesas o francesas al ofdo español de Alonso Váquez. Al hablar, por ejemplo de la fabricación de diversas clases de cerveza y del consumo de esta bebida n acional flamenca, nuestro bravo soldado dice lo siguiente: "La cerveza de cebada es más sana y no emborracha tanto y es más barata. Ia de avena y centeno tiene su más y menos, y diferencian en el color y en la fuerza y precio. La de salvado es la más barata y sin ninguna sustancia; llámanla en flamenco, demuir, que quiere decir pequeña cerveza, y los valones la dicen petitabiera; a la de trigo, cerveza doble; a la de cebada, entredoble, $y$ en esta conformidad las nombran siempre que las han de comprar o beber' ${ }^{3}$. Las palabras demuir y petitabiera de este pasaje constituyen una españolización individual o simplemente la percepción española respectivamente de la palabra holandesa (flamenca) dunbier 'cerveza de calidad inferior' ${ }^{\text {y }}$ y de la voz francesa (valona) petite bière 'cerveza que contiene menos alcohol'. El que Alonso Vázquez diga: «lámanla en flamenco, demuir, que quiere decir pequeña cerveza y los valones la dicen petitabieral nos muestra muy bien el ambiente holandés (flamenco)-francés (valón)-español de los Países Bajos en la segunda mitad del siglo xvI.

1 AI.onso VরzQUez, Los sucesos de Flandes y Francia del tiempo de Alejandro Farnese por el capitán Alonso Vazquez, sargento mayor de la milicia de Jaen y su distrito, escrito en diez $y$ seis libros, en Colección de Documentos inéditos para la

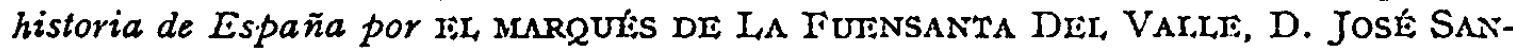
cio Rayón y D. Francisco de Zabaliburu. Madrid, I879, \$. LXXII, pp. V-XV.

2 VAzQUEZ, Los sucesos, t. LXXII, p. 38.

3 VAzQUEZ, Los sucesos, t. LXXII, pp. $4 \mathrm{I}-42$.

- Véase el holandés dunnebier, dunbier (holandés dun 'floja' + bier 'cerveza') en el Woordenboek der Nederlandsche taal. Ia Haya y Leiden, Igr6, t. IIr, I916, p. 3662. 
Asf́ como transformó o españolizó Alonso Vázquez la palabra holandesa dunbier en demuir y la francesa petite biere en petitabiera, convirtió también al español el francés caremesse o el medio neerlandés (flamenco) kermesse, carmesse en caramesia en la misma frase en que hizo de la voz holandesa ongang 'procesión' la española humeganga. (véase más arriba). (Citemos también el flamenco hannekenuit 'guardia nocturno, sereno' 1, convertido por Alonso Vázquez en haniquenne 0 . haniquenuquie ${ }^{2}$ en español, o igualmente los nombres de las ciudades. holandesas Vlissingen y Bergen-op-Zoom, que en castellawo de nuestro capitán se convierten, respectivamente, en Freselingas, Pechelingas ${ }^{3}$ y Bergas Olzon 4). La voz caramesia es, pues, un término aislado y creación personal de Alouso Vázquez, quien la sacó del francés caremesse - del medio neerlandés (flamenco) kermesse, carmesse parą indicar la popular y típica fiesta flamenca. Observemos también que más tarde, en I646, tenemos la siguiente documentación, asimismo aislada, de esta palabra en La vida y hechos de Estebanillo González: "Al fin, habiendo echado algunos bajeles a fondo, y cogido presas de importancia, nos volvimos la vuclta de Flandes, ayudados de un poniente favorable. Era una alegre fiesta de caranesa el vernos cuán bien lográbamos los ratos desocupados que teníamos, porque como el vino no nos habia costado nada, bebíamos todos a discreción.... ${ }^{5}$. El autor de esta obra, laciendo la descripción interesantísima de la vida, costumbres y lenguaje de la soldadesca española de Flaudes, con la cual convivió durante su viaje, ha usado, como Alonso Vázquez, por su parte la palabra caramesa, de base francesa u holandesa (flamenca) ${ }^{\circ}$.

La voz española kermesse la encontramos en la.Enciclopedia EspasaCalpe: «kernesse. Dícese en Holanda, Bélgica y N. de Francia de las fiestas parroquiales y ferias anuales que allf se celebran con grandes

1 Véase el flamenco hanneken-ıit, hannenuit en el Woordenboek der Nederlandsche taal, t. V, rgoo, p. 2 rog.

2 .... Hámanle hantiquennze, que quiere decir guardia del fuego, y sirve de andar toda la noche por las calles de su parroquia dando voces, con una alabarda en la mano y una lanterna encendida y un gran perro al lado que le acompaña, y dice que maten las luces y se acuesten, y tiene la obligación de decir siempre la hora que es ... Además del salario que tienen estos haniquenuques, les dan en cada casa el dia de año nuevo su aguinaldo..." (VAzQUEZ, Los sucesos, IXXII, p. 46).

3 VAzQUEZ, Los sucesos, t. IXXII, pp. I82, 429; t. LXXIII, pp. 252, 352.

- VAzQUEZ, Los sucesos, t. LXXII, pp. 3I7, 45I; t. IXXXII, p. 392.

5 La vida y hechos de Estebanillo González hombre de buen humnor compuesta

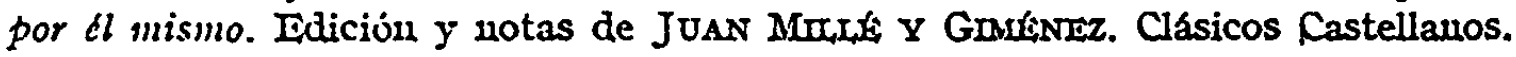
Madrid, Ispasa-Calpe, 1934, t. II, pp. 247-248.

- La vida y hechos de Estebanillo Gonzdlez, t. I. Prólogo, p. I8. 
regocijos. En dichos paises estas fiestas son muy distintas, pues la feria constituye en esta última nación un elemento esencial... En España se ha introducido recientemente esta voz para designar ciertas fiestas organizadas, por lo comin, para fines benéficos... [el subrayado es mío]" ${ }^{2}$. $\mathrm{Y}$, en efecto, en comprobación de lo afirmado por el redactor de este artículo de la Enciclopedia, documentamos la palabra kermesse ya algunos años antes, empleada en dicho sentido, en las novelas Camino de perfección (I902) y La Busca (r904) de Pio Baroja y en un artículo de la revista Nuevo Mundo (Madrid, I6 de octubre de I9I3) ${ }^{1 \text { bis. El }}$ Pequeño Larousse Ilustrado, adaptación española del pequeño Latousse francés, efectuada por Miguel del Toro Gisbert, inserta también la palabra kermesse ${ }^{2}$. Es muy probable que dicha palabra kermesse pasara de este diccionario al diccionario español-holandés y holandés-español de van $\mathrm{Dam}^{3}$. El hecho de que tanto el Pequeño Larousse como el diccionario de van Dam citen a los Teniers (padre e hijo), famosos pintores flamencos de kernesses del siglo xvm, nos inclina a deducir que la fuente común de ambos diccionarios haya sido el Larousse francés. Ėn resumen, puede decirse que, en tanto que la voz española kermesse es término

1 Enciclopedia Universal ilustrada europeo-americana. Espasa-Calpe. BilbaoMadrid. Barcelona, t. 28, I926, s. v. kermesse.

do En el capitulo III del Camino de perfección se lee: "Dias más tarde, al llegar Fernaudo a su casa, se encontró con una invitación para ir a una kermesse que se celebraba en el Jardin del Buen Retiro (Edición conmemorativa del Centenario del nacimiento de Pio Baroja. Madrid, Caro Raggio, 1972, p. 21) y en el capitulo VII de La Busca se lee: "IJa Kermesse de la calle de la Pasión fué esperada por Leandro con ansiedad. Otros años habia acompañado a la Milagros a la verbena de San Antonio y a las del Prado; bailó con ella, la convidó a buũuelos, la regaló un tiesto de albahaca; aquel verano, la familia del Corretor parecia tener empeño decidido de apartar a Milagros de Leandro. Este se enteró de que su novia y su madre pensaban ir a la kermesse, y se agenció dos billetes, 8 anunció a Manuel que los dos se presentarian allá" (Obras completas. Madrid, 1946, I. p. 3ro). El articulo de la revista Nuevo Mundo se titula "La Kermesse de la Latina" y, en un pasaje de él, se lee: "Y llega el dia de la Kermesse de la Latina, con su correspondiente tómbola..."

2 «oumbre que se da en los Paises Bajos a las fiestas parroquiales celebradas con motivo de las ferias, con gran solemnidad: Teniers es el pintor de las kermesses. Neol. Fiesta de caridad, feria, diversión" (Pequeño Larousse Ilustrado. Paris, I931, s. v. kermesse). "En pays de langue flamande, fêtes paroissiales, foires aunuelles célébrécs avec grandes rejouissance: Teniers est le peintre des kermesses" (Nouvear6 Petit Larousse Illustre. Paris, 1946, s. v. kermesse).

3 C. F. A. VAN DAir, Spaans Handwoordenboek. Eerste Deel. Spaans-Nederlands. La Haya, I932, s. v. kermesse «kermis». Tweede Deel. Nederlands-Spaans. Ia Haya, I937, s. v. kermis "feria, kermesse, verbena... cuadro de una kermesse; een kermis van Teniers, una kermesse de Teniers». 
libresco ${ }^{1}$, introducido recientemente del francés ${ }^{2}$, y ambientado después de modo especial en España ${ }^{3}$, carames(i)a es creación espontánea del capitán español Alonso Vázquez y del autor de La vida y hechos de Estebanillo González, de base flamenca o francesa.

En el curso de este estudio hemos tratado: por un lado, las relaciones económicas (importaciones de tejidos) entre España y los Países Bajos durante los siglos XIr, XIII y Xrv; por otro lado, las relaciones de ambos países durante los siglos XV, XVI y XVIr, a causa de las guerras de Flandes y por ser, además, los Paises Bajos en aquella época parte integrante de la monarquía española. Como consecuencia de estas relaciones, hallamos en castellano palabras tomadas en préstamo del holandés (flamenco) y palabras creadas de base holandesa (flamenca). Para denominar los tejidos importados en los siglos XIr-XIV de las ciudades flamencas Ypres, Gante y Brujas, y que carecian entonces de nombre, se crearon nombres españoles: ypre, gante, brujas.

Por lo que toca a los préstamos holandeses (flamencos) en castellano, el problema principal reside en establecer si son voces de introducción directa o bien indirecta, a través del francés. Como en francés existen más de 800 voces de procedencia holandesa ${ }^{4}$ y dado que en los Paises Bajos, en los siglos xVI y xvIr, nos hallamos en un ambiente francésholandés (flamerico)-español y que, en la parte meridional de estos países, el francés era entonces de uso general y corriente ${ }^{5}$, es fácil comprender que las voces holandesas llegasen al castellawo a través de este grau almacén de palabras holandesas que es el francés. Queda, pues, una cantidad ínfima de palabras españolas que proceden con seguridad directamente del holandés. Por ahora, sin una investigación orgánica y a fondo, basada principalmente en los textos, no podemos dar siquiera una cifra aproximada de los préstamos holandeses directos en español, que son ciertamente escasísimos.

\section{B. E. VIDOS}

2 Para palabras librescas, véase Vidos, Prestito, pp. 36r-362, 373, 373.

- Hay que aũadir que la palabra kermesse en portugués está considerada como un barbarismo inwecesario, cfr. C. DE FIGUIIREDo, Novo dicionário da lingua portuguesa. Lisboa, I925, s. v. kermesse Estrangeriswo inútil, por feira com arraial, bazar. (Fr. kermesse)", D. DE AzEVEDO, Grande diciondrio francésportuguis. Lisboa, r952, s. v. kermesse "Quermesse, nome das festas e feiras anuais que se celebram na IIolanda, na Bélgica e em Flandres con grande regozijo, no dia do orago das parćquias".

3 Pequeña Enciclopedia Columbus. Diccionario enciclopédico popular ilustrado de la lengua castellana. Barcelona, 1934, s. v. kermesse Barbarismo. Verbenan; J. CASARES, Diccionario ideológico de la lengua española. Barcelona, Ig66, s. v. Kermesse Nerbena, fiesta popular // Iiesta benéfica con rifas, tómbola etc."

- VAsRnoff, Echanges, p. I2.

- MI. VAlKuOFF, De expansie van het Nederlands. La Haya, I94I, pp. 72-74. 